\title{
Visualization Investigation of Energy Dissipation Induced by Eddy Currents for a Solitary-Like Wave Passing over Submerged Breakwater Sets
}

\author{
Chi-Yu Li ${ }^{1,2}$, Ruey-Syan Shih ${ }^{3, *}$ a and Wen-Kai Weng ${ }^{3}$ \\ 1 Bachelor Degree Program in Ocean Engineering and Technology, National Taiwan Ocean University, \\ Keelung 20224, Taiwan; chiyuli@ntou.edu.tw \\ 2 Center of Excellence for Ocean Engineering, National Taiwan Ocean University, Keelung 20224, Taiwan \\ 3 Department of Harbor and River Engineering, National Taiwan Ocean University, Keelung 20224, Taiwan; \\ wkweng@mail.ntou.edu.tw \\ * Correspondence: rsshih@mail.ntou.edu.tw; Tel.: +886-2-24622192 (ext. 6107)
}

Received: 18 September 2020; Accepted: 21 October 2020; Published: 22 October 2020

\begin{abstract}
Wave attenuation for the purpose of coastal protection has been an important topic in coastal engineering. Wave attenuation in relation to the vortices induced by a solitary-like wave propagating over submerged breakwaters (BWs) is discussed in this paper. A series of hydraulic model experiments was conducted to investigate the occurrence of eddies, the types and combinations of submerged BWs, and related phenomena of the range expansion of vortices. The microscopic changes in the flow field, the variation of eddies, and the distributions of streamlines were analyzed using the particle image velocimetry (PIV) technique. The measured transmission and reflection coefficients, along with the concept of energy conservation, were also examined to support the results. The results indicate that the attenuated wave energy is related to the induced vortices, and show that the total relative vortex energy for rectangular submerged BWs is larger than that for undulating submerged BWs in both the single and composite sets. The magnitude of the maximum vorticity of the undulating BW sets is larger and more concentrated than that of the rectangular BW sets; however, the total vortex energy is slightly smaller owing to the narrower vortex area range.
\end{abstract}

Keywords: particle image velocimetry; solitary wave; submerged obstacle; undulating breakwater; rectangular breakwater; vortex energy

\section{Introduction}

Waves are regarded as a form of energy transmission. Offshore waves can cause damage to coastal structures, which often comprise the infrastructure protecting lives and property. Coastal protection has therefore been an important topic in the field of coastal engineering. For this reason, various types of structures, including submerged artificial levees, breakwaters (BWs), and floating obstacles, have been studied to reduce the damage caused by waves. One approach to address these issues is to evaluate wave-structure interactions, and investigate how wave energy is attenuated. The physical characteristics of various types of undulating and sinusoidal topographies interacting with waves have been studied. Davis and Heathershaw [1] investigated the attenuation of surface-wave propagation over sinusoidally varying topography. Dalrymple and Kirby [2] investigated the interactions of small amplitude water waves with a patch of bottom ripples using the boundary integral equation method (BIEM). O'Hare and Davis [3] presented a method for modeling surface wave propagation over undulating topography. Kar et al. [4] analyzed the gravity wave transformation with a finite floating dock in the presence of bottom undulation trenches. Undulating topography has been applied and designed by Shih and Weng [5,6] and Shih et al. [7] as BWs, and the effectiveness of 
regular waves, irregular waves, and long wave attenuation was discussed in relation to their physical experiments. However, the interaction of the wave structure and the relationship between wave energy attenuation and vortices, especially the vortices induced by those undulating BWs, have not been widely investigated through experimental visualization.

In early research on the visualization of obstacle-induced vortices, Hino and Yamazaki [8] discussed the vortex formation and energy dissipation of periodic waves passing through vertical plates in a tank with dimensions $20 \mathrm{~m}$ long and $0.4 \mathrm{~m}$ wide. Viewed from the side, a $16 \mathrm{~mm}$ camera was used to shoot continuously at $12 \mathrm{fps}$. The hydrogen bubbles used to track the particles were generated by electrolysis with the application of a high DC voltage to the anode of a copper plate. The results showed that the energy dissipation rate can be estimated by the resistance coefficient. Ikeda et al. [9] investigated the vortex structure and energy dissipation near both sides of the edge of a vertical plate under wave action, and discussed the discrete vortices created by a submerged dike and the estimation of transmitted waves. It was found that the vortex can be numerically simulated with Lamb-Oseen vortices, confirming that the wave energy is dissipated as a result of the formation of the vortices. Hokamura et al. [10] studied the energy dissipation of eddies around the tip of a double-barrier floating breakwater (DBFB) using the dye flow visualization technique. The results showed that the reduction in wave height was caused by the loss of wave energy due to the vortex motion separated by the vertical plate tip. The DBFB caused vortices at the tips of two vertical plates, and these were widely distributed on the width scale of the floating body. The characteristics of velocity field variations when a solitary wave propagates over a reverse flow field were studied by Umeyama [11] using the super-resolution particle image velocimetry (PIV) technique. The velocity fields and flow patterns near a vertical and an inclined thin plate obstacle, induced by the propagation of a solitary wave, were also investigated by Zaghian et al. [12] using the PIV technique. Jiao et al. [13] investigated the flow field around three reefs using the PIV technique, which was used to validate the numerical simulation. Their simulation results showed good agreement with the results of the PIV experiments. Chang et al. [14] studied the interaction between a solitary wave and a vertical thin plate installed at the bottom, and discussed the fluid kinematics and vortex modes caused by the wave. Lin et al. [15] used the high-speed particle image velocimetry (HSPIV) technique to explore the dissipation process of solitary wave energy on very steep beaches, including its acceleration and pressure-gradient characteristics.

In order to determine the relationship between wave energy attenuation and vortices induced by submerged BWs, a series of hydraulic model experiments was conducted to investigate the eddy formation and flow field distributions generated by the interactions between waves and submerged structures in this study. The wave is a solitary-like wave generated by a landslide wave generator, and the submerged structures consist of a single set and a composite set of rectangular and undulating BWs. All experiments were filmed with a high-speed digital camera, and were analyzed using the digital particle image velocimetry tool PIVlab $[16,17]$. The distribution of the eddy velocity field and the vorticity strength were analyzed, and the results were used to calculate the proportion of eddy energy in the entire wave energy attenuation process. In addition, the measured transmission and reflection coefficients when the wave propagated over the submerged BWs, along with the concept of energy conservation, were adopted to confirm the calculations. Furthermore, the different properties of vortices and the distributions of streamlines induced by different submerged BWs are also discussed.

\section{Experimental Setup and Methods}

In this study, the flow field and formation of the vortices induced by the interaction between the generated solitary-like wave and different sets of submerged BWs were investigated experimentally. The model experiments were conducted in a two-dimensional open channel, which was about $5.0 \mathrm{~m}$ long, $0.08 \mathrm{~m}$ wide, and $0.2 \mathrm{~m}$ deep. The flume layout and experimental setup are schematically shown in Figure 1. Long waves, such as tsunamis, or waves resulting from large displacements of water, for example landslides and earthquakes, sometimes behave approximately like solitary waves. It is difficult to form a truly solitary wave in nature because trailing small dispersive waves are 
usually formed. Different generators of solitary or impulse waves have been widely adopted in many physical experiments to study the effects of long waves, including piston-type wave generators $[18,19]$, Scott Russell wave generators [20,21], and landslide tsunamis [22-24]. In this study, a solitary-like wave generated by a sliding body was adopted. As can be seen in Figure 1, a landsliding system was adopted to serve as a solitary wave generator at the left end of the flume, and a solitary-like wave was generated by a concrete block sliding down a $\alpha=67.5^{\circ}$ slope. The generated solitary-like wave propagated from left to right, and a fixed vertical baffle with the same height as the water depth was installed to reduce reflected waves from the end wall. This is because the waveform and volume of the solitary waves are mainly above the water surface, and the waves can pass directly over the baffle and into a container when they reach the end of the flume. The water depth $h$ was maintained at a constant $0.1 \mathrm{~m}$, and sets of submerged BWs were placed $2.5 \mathrm{~m}$ away from the wave generator. The visualization area was set to focus on the environment surrounding the submerged BWs, as shown in Figures 1 and 2, which show a photograph of the experimental setup and the wave vortex measurement.

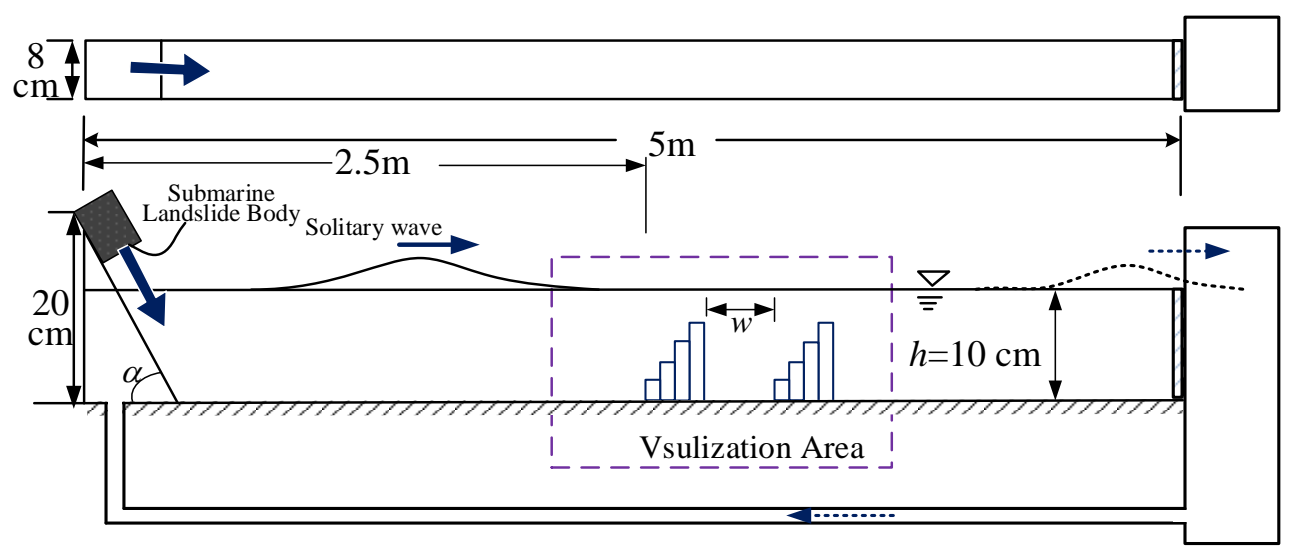

Figure 1. Schematic layout of wave flume and experimental setup.

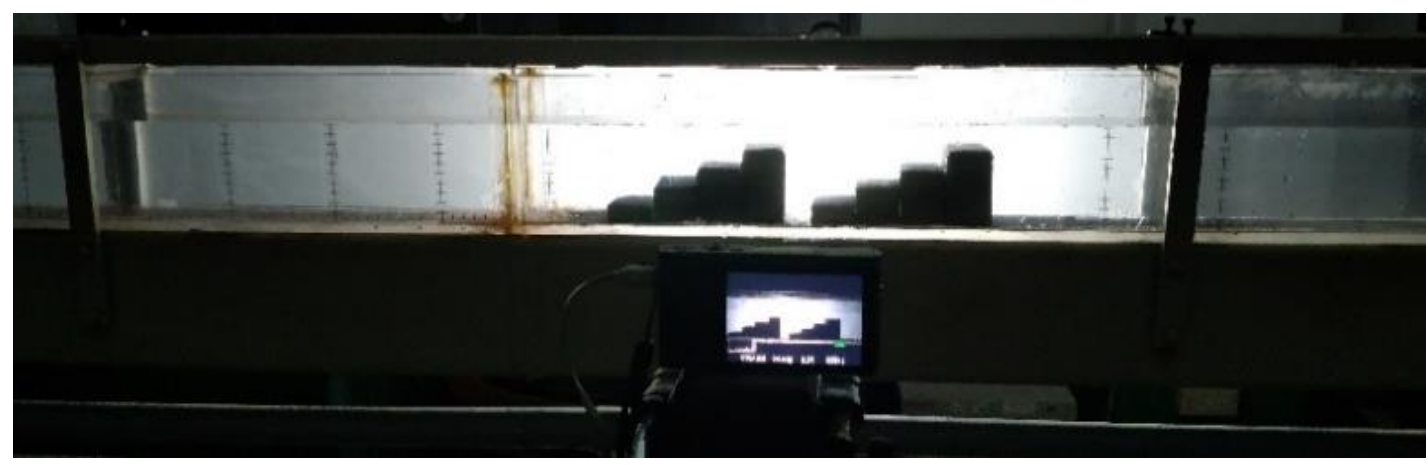

Figure 2. Experimental setup and wave vortex measurement.

A set of submerged BWs was composed of four blocks of different heights and the same width, of $0.04 \mathrm{~m}$, arranged in an ascending step formation from upstream to downstream. Their heights as a proportion of the water depth were $0.2,0.4,0.6$ and 0.8 , respectively. Figure 3 shows photographs of rectangular and undulating BW sets, resembling stair-step structures and underwater sand dunes, respectively, made of concrete material, as used in the experiments. A combination of two submerged BW sets, either both single or both composite sets, with the separation distance relative to the water depth $w / h=0.4$, was also discussed in this study, as listed in Table 1 . 


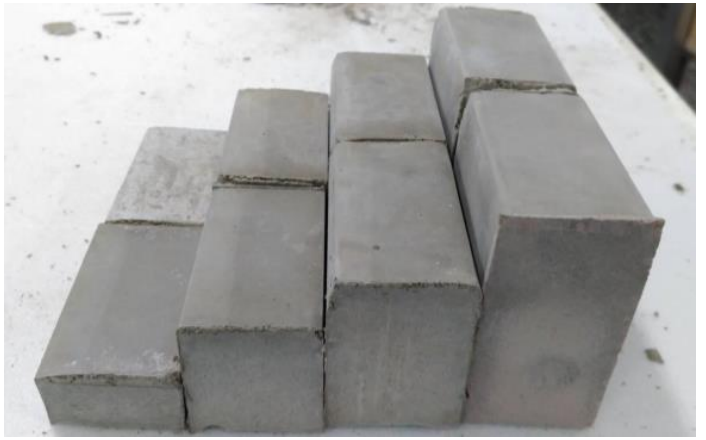

$(\mathbf{a})$

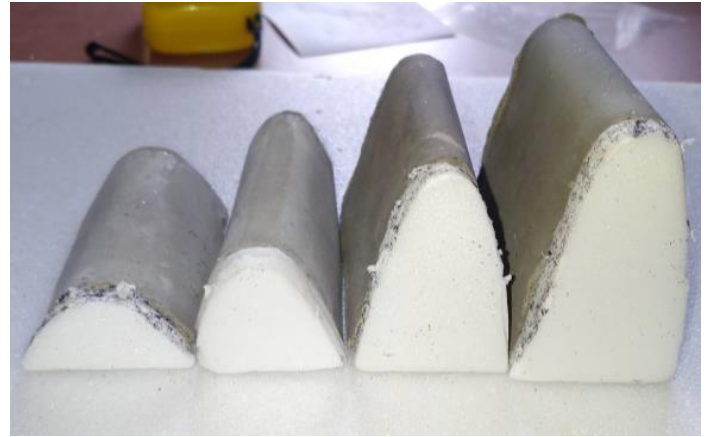

(b)

Figure 3. Single (a) rectangular and (b) undulating breakwater set.

Table 1. Combination of breakwaters sets.

\begin{tabular}{cccc}
\hline Breakwater Type & Schematic Diagram & $\begin{array}{c}\text { Breakwater Height } \\
d / h\end{array}$ & $\begin{array}{c}\text { Separation Distance } \\
w / h\end{array}$ \\
\hline Single Set & $0.2,0.4,0.6,0.8$ & - \\
Composite Set & & & \\
\hline
\end{tabular}

A high-speed digital camera with a maximum frame rate of $960 \mathrm{fps}$ at specific resolutions recorded the changes in the waveform to confirm the results measured by the wave gauges. At the highest resolutions, the camera supported images and/or videos with a resolution of up to $1920 \times 1080$ pixels. The video images were captured at different time intervals in the highest resolution for analysis. PVC-based glitter powder with a particle size of approximately $0.05 \mathrm{~mm}$ and a measured settling speed of $7.592 \mathrm{~mm} / \mathrm{s}$ on average was chosen for use as the seeding particles. In this arrangement, the shooting observation range was relatively wide, and the tracking particles became comparatively blurred when shooting at $960 \mathrm{fps}$. To ensure the best results, a shooting speed of $480 \mathrm{fps}$ to conduct the experiment was used in this study.

The digital particle image velocimetry tool for MATLAB, named PIVlab [16,17], was chosen as the PIV tool to analyze the captured images. With proper settings, including image preprocessing using contrast-limited adaptive histogram equalization (CLAHE), the cross-correlation of continuous image data could be derived. From this, the physical properties of the flow field, for example, horizontal velocity, $u$, vertical velocity, $v$, vorticity, $\omega$, velocity intensity magnitude, and velocity vector angle, $\theta$, which describe the wave-structure interactions for the generated solitary-like waves propagating over submerged BWs, could be derived.

According to Hino and Yamazaki [25], eddy capacity can be estimated by the kinetic energy per unit width of a vortex, that is, the calculated eddy energy. This can be expressed as:

$$
E_{v}=\frac{\rho}{2} \int_{0}^{a} 2 \pi r q^{2} d r=\frac{1}{16} \pi \rho \omega^{2} r_{0}^{4}\left(1+4 \ln \frac{a}{r_{0}}\right)
$$

where $\omega$ is the vorticity, $\rho$ is the water density, $r$ is the distance to the vortex center, $r_{0}$ is the radius of the boundary between the vortex area and the vortex-free area, and $a$ is the maximum radius of the vortex representing the outer limit of the vortex, that is, $r_{0}<a$, according to Hino and Yamazaki [25]. 
In addition, the speed $q$ in the circumferential direction at radius $r$, and the vortex strength $\Gamma$ (circulation), can be determined by

$$
\begin{gathered}
q=\frac{\omega}{2} r \\
\Gamma=\omega \pi r^{2}
\end{gathered}
$$

These physical properties of the flow field, including the horizontal velocity, $u$, vertical velocity, $v$, and speed, can be derived from each interrogation window during the PIV analyses using PIVlab. Therefore, the vorticity can be determined by

$$
\omega=\frac{\partial v}{\partial x}-\frac{\partial u}{\partial y}
$$

According to the Coastal Engineering Research Center [26], the total energy of a solitary wave can be expressed as

$$
E_{0}=\frac{8}{3} \rho g h^{2} H \sqrt{H / 3 h}
$$

where $H$ is the solitary wave height and $h$ is the water depth.

\section{Experimental Validation}

To confirm the appropriateness of applying the above-mentioned methods to the generated solitary-like waves and measured flow field by using PIV analyses, the measured waveform was compared with the theoretical results, and the cross-sectional distribution of the flow velocity in the flume was also verified using measurements made by an acoustic Doppler velocimeter (ADV).

\subsection{Validation of the Solitary Wave Generation}

As mentioned in the previous section, a solitary-like wave was generated by a landsliding system with a sliding concrete block. In order to confirm whether the analysis methods mentioned above were appropriate, the experimental wave elevation measured by two capacitance wave gauges was compared with the theoretically calculated elevation. Figure 4 shows a comparison of the experimental distribution of water elevation (waveform) and the theoretical distribution derived by the Boussinesq equation [27]:

$$
\eta=\operatorname{sech}^{2}\left(\sqrt{\frac{3 H}{4 h^{3}}(x-c t)}\right)
$$

where $\eta$ represents the water level and $c$ is the wave speed. The comparison shows a satisfactory agreement between the experimental and theoretical results.

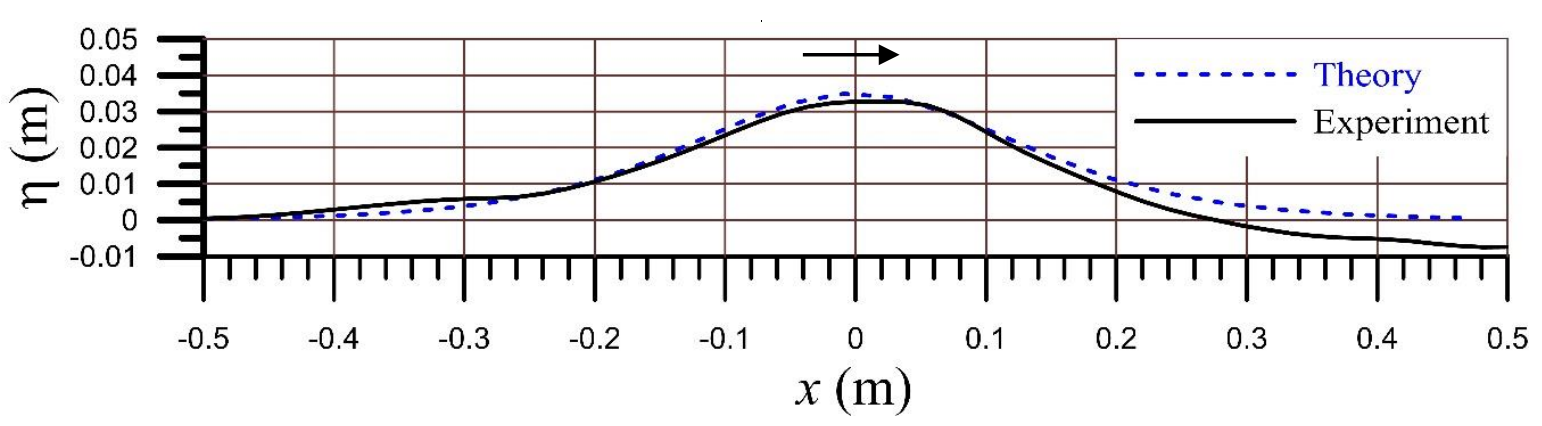

Figure 4. Comparison of measured waveform with the theoretical one. 


\subsection{Validation of the PIV-Analyzed Velocity Field}

In order to confirm the applicability of the velocity field computed by the PIV analyses using PIVlab, the vertical water velocity profiles as measured by the ADV in a water tank with a controlled flow rate were compared to the PIV analyses. This approach was also conducted by Song and Chiew [28] and Ruonan et al. [29]. The ADV used in our study was a Vectrino (Nortek AS), as shown in Figure 5. A comparison of the vertical water velocity profiles derived by ADV and PIVlab with a controlled flow rate is shown in Figure 6. The cross-sectional average flow velocity was approximately $0.049 \mathrm{~m} / \mathrm{s}$ in the water tank, serving as a reference for confirmation. According to the outlet velocity distribution along the cross-sectional direction of a current field without waves, the difference between the results from the PIV analyses using PIVlab and ADV is approximately 5.276\%. More detailed information regarding the accuracy tests of the PIVlab can be found in a previously reported study [17].

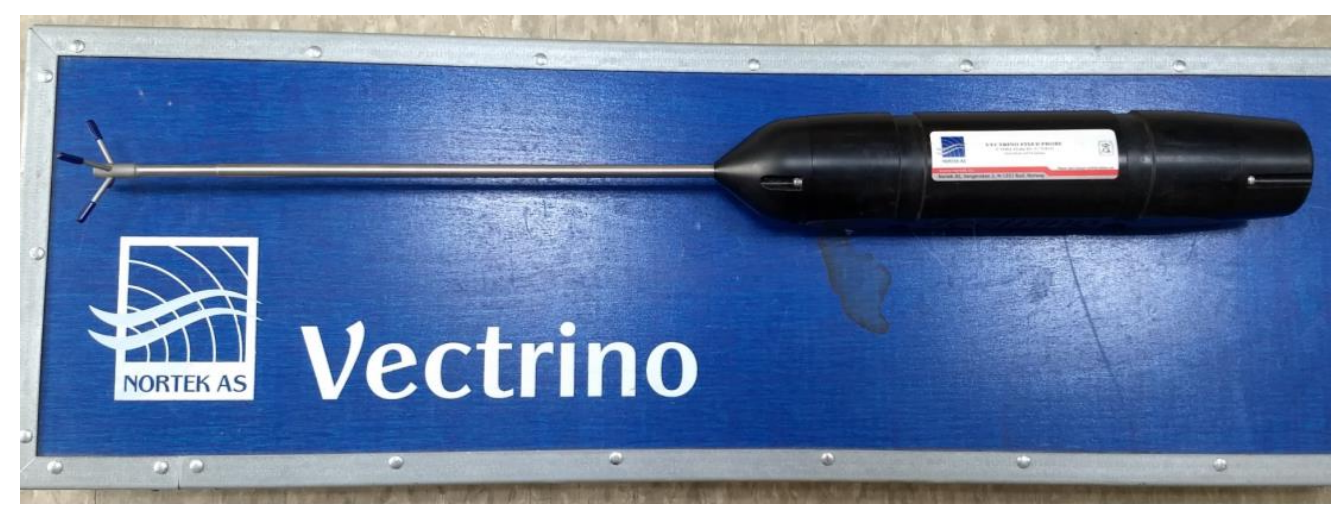

Figure 5. The acoustic Doppler velocimeter for the validation of the PIV-analyzed velocity field.

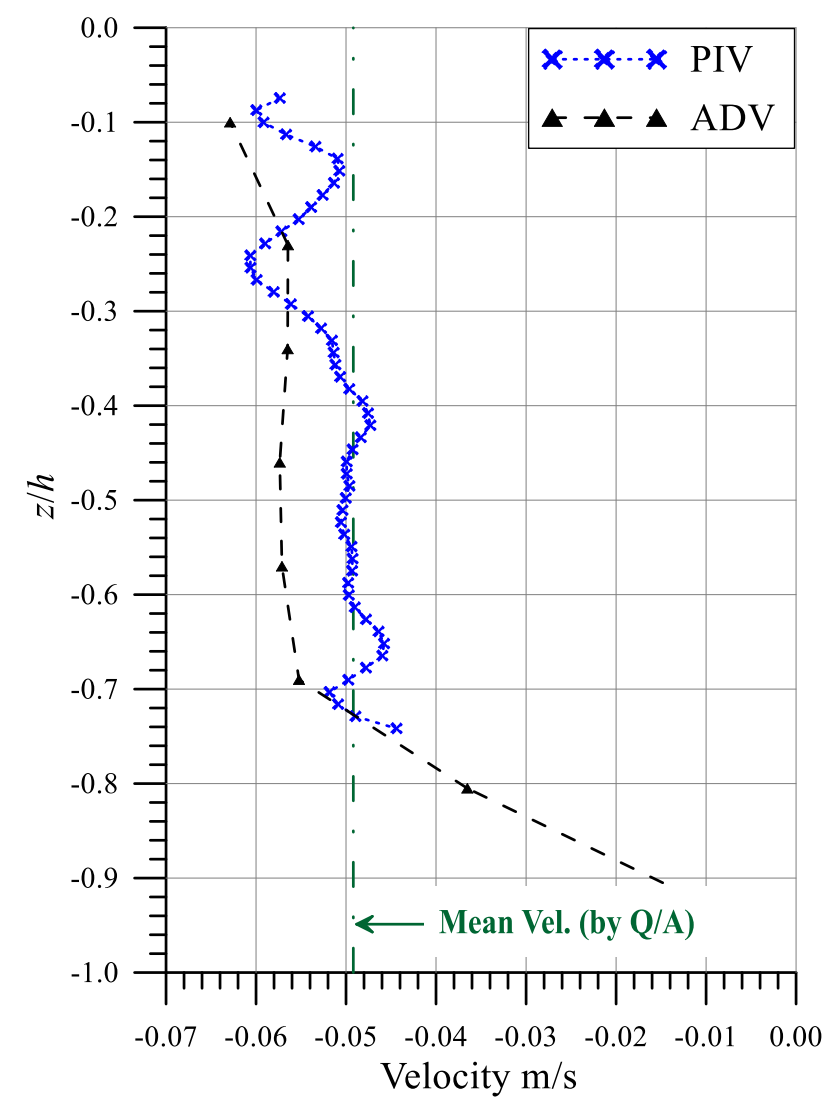

Figure 6. Comparison of the vertical velocity distribution derived by the acoustic Doppler velocimetry (ADV) and the particle image velocimetry (PIV) analyses. 


\section{Results and Discussion}

\subsection{Relative Vortex Energies Induced by a Single Set of Rectangular and Undulating BWs}

The temporal variation of the flow field and the induced vortex when the generated solitary-like wave propagated over a single set of submerged rectangular and undulating BWs is presented in Figure 7. The data presented were derived from the PIV analyses, and the arrows represent the incident wave direction. From the circumferential velocity and vorticity, together with the current radius of each point, the effective eddy capacity can be calculated. The value of $r_{0}$ is determined by the maximum value of the positive and negative velocities, which usually occurs on the periphery of the vortex area. Based on the relative position of the vortex, the center of the entire vortex field is determined, and the energy distributions of each particle around the center point are obtained.
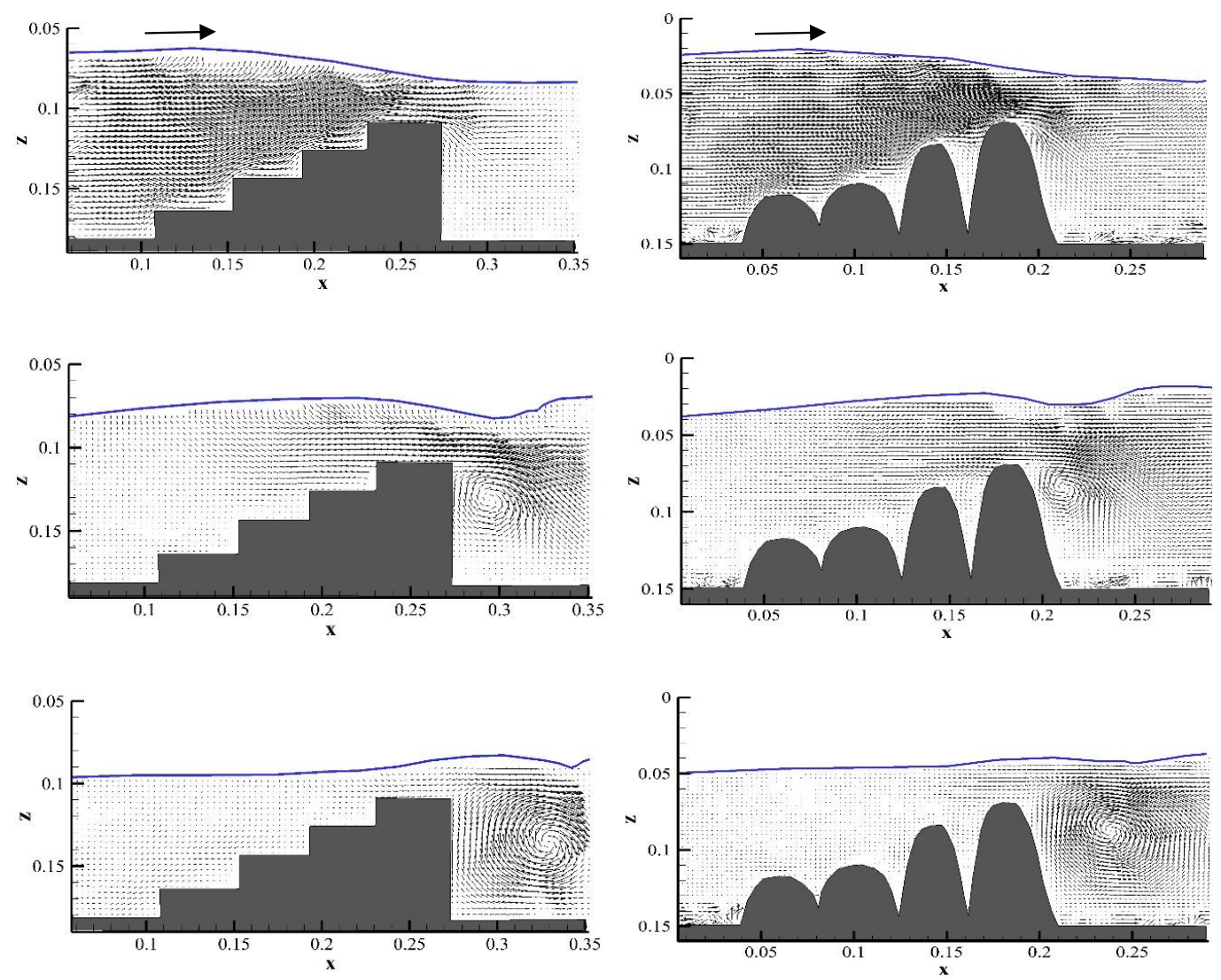

(a)

(b)

Figure 7. The vortex and velocity distribution around a single set of submerged breakwaters: (a) rectangular submerged breakwater; (b) undulating submerged breakwater.

When observing the eddy current phenomenon of a single set of submerged BWs, it can be noticed that some smaller local vortices exist in the middle of the submerged BWs. The vortices induced by rectangular or undulating submerged BW sets are difficult to assess. However, the determination of the intensity of the vortex energy is mainly related to the intensity of the vortex. Therefore, the maximum vortices appearing behind the submerged BWs were derived from the subsequent results derived from the PIV analyses. From analysis of the vortex intensity, the maximum vorticities around the center of the vortex were $55.031 / \mathrm{s}$ and 107.81 //s for a single set of rectangular and undulating submerged BWs, respectively, as shown in Figures $8 \mathrm{a}$ and 9a. Accordingly, the total relative vortex energy for a single set of rectangular submerged BWs was approximately $65.09 \%$, with $a=0.051 \mathrm{~m}$ and $r_{0}=0.025 \mathrm{~m}$, and the total relative vortex energy behind a set of undulating submerged BWs was approximately 50.63\%, 
with $a=0.051 \mathrm{~m}$ and $r_{0}=0.022 \mathrm{~m}$, as shown in Figures $8 \mathrm{~b}$ and $9 \mathrm{~b}$. In addition, the transmission coefficient $K_{t}$ and reflection coefficient $K_{r}$ could be estimated via the ratio of the transmitted wave height to the incident wave height, and the ratio of the reflected wave height to the incident wave height, according to Goda and Suzuki [30] and Mansard and Funke [31]. The estimated transmission coefficient $K_{t}$ and reflection coefficient $K_{r}$ were, respectively, approximately 0.509 and 0.273 for a single set of rectangular submerged BWs, and approximately 0.811 and 0.178 for the single set of undulating submerged BWs, respectively. Moreover, from the concept of energy conservation, the sum of energy attenuation could be calculated from the equation $K_{L}=\sqrt{1-K_{r}^{2}-K_{t}^{2}}$, and this was found to be approximately 0.816 for the rectangular submerged BWs and 0.558 for the undulating ones.

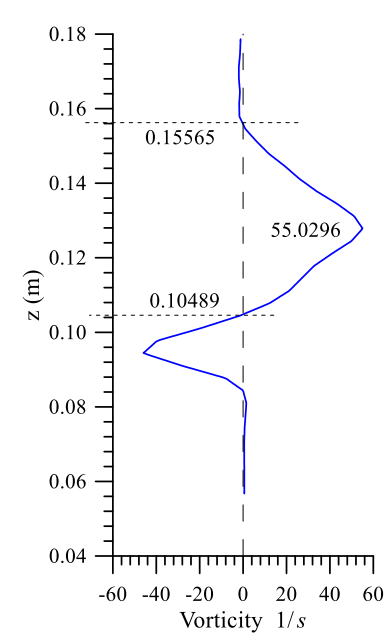

(a)

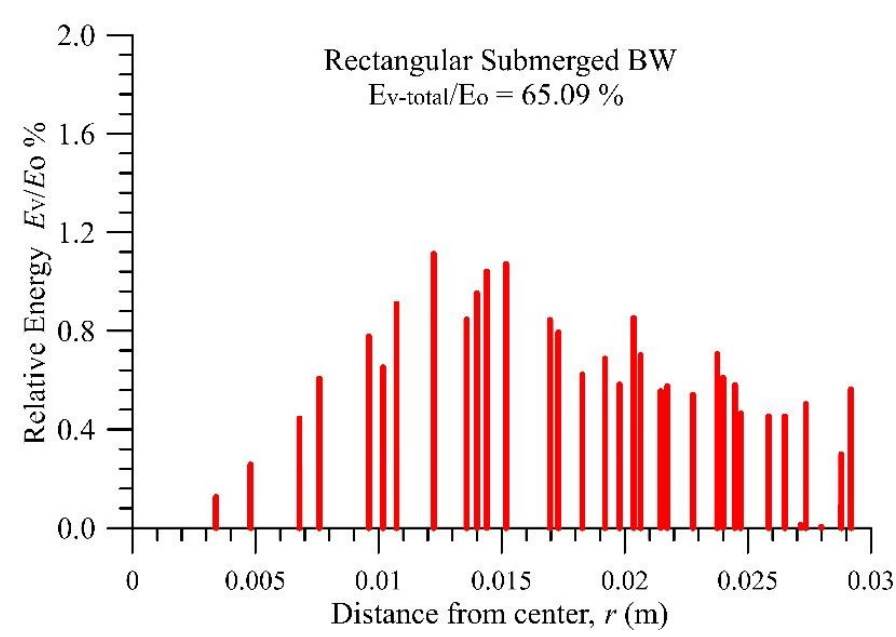

(b)

Figure 8. The vorticity and relative energy of the maximum vortex induced by a solitary-like wave propagating over a set of rectangular submerged breakwaters: (a) the vorticity distribution along the vertical line of the vortex center; $(\mathbf{b})$ the relative vortex energy distribution.

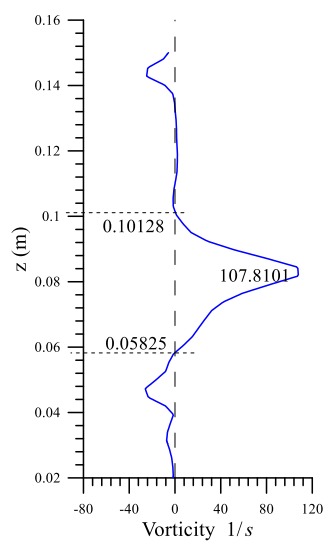

(a)

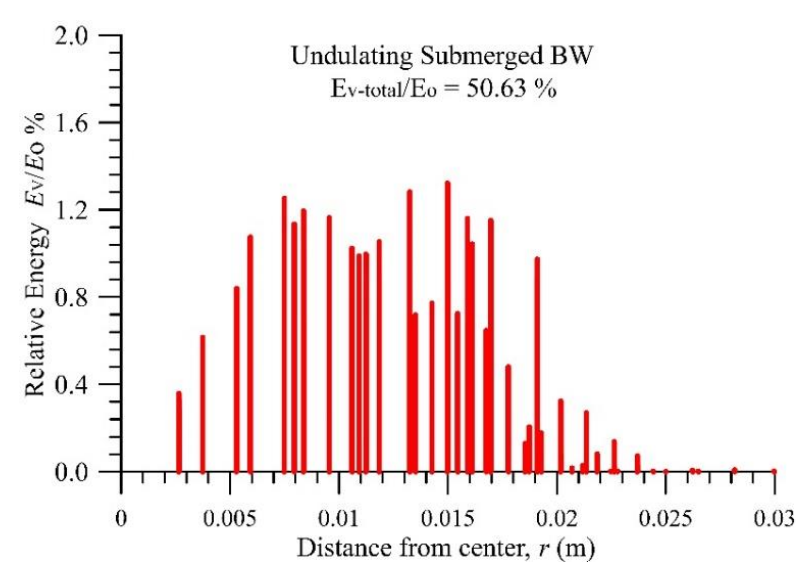

(b)

Figure 9. The vorticity and relative energy of the maximum vortex induced by a solitary-like wave propagating over a set of undulating submerged breakwaters: (a) the vorticity distribution along the vertical line of the vortex center; (b) the relative vortex energy distribution.

The results of the above-mentioned analyses show that the total vortex energy induced by a set of rectangular submerged BWs appears to be slightly larger because the vortex area range is wider than that of the undulating BW-induced vortex, although the maximum vorticity of the former is relatively smaller. In addition, the relative vortex energy percentage of the submerged BW-induced vortices 
shows that the main concentration range of vortex energy lies between $0 \mathrm{~m}$ and $0.03 \mathrm{~m}$ for the single set of rectangular submerged BWs, as shown in Figure 8b, and between $0 \mathrm{~m}$ and $0.025 \mathrm{~m}$ for the single set of undulating submerged BWs, as shown in Figure $9 \mathrm{~b}$. Moreover, the maximum relative energy, $E_{v} / E_{0}$, is approximately $1.12 \%$ for the single set of rectangular submerged BWs and approximately $1.36 \%$ for the single set of undulating submerged BWs. This shows that the rectangular submerged BW-induced vortex is relatively divergent, whereas the undulating submerged BW-induced vortex is relatively concentrated. $E_{v}$ and $E_{0}$ denote the energy of the induced vortex and incident wave, as determined by Equations (1) and (5), respectively, and the variation of vorticity distribution through the vertical line of the vortex center can be obtained from the PIV analysis process using PIVlab.

Figures 10 and 11 show the temporal variation and distribution of streamlines when a solitary-like wave propagates over a set of rectangular or undulating submerged BWs, respectively. It can be clearly seen that some local small eddies occurred between the steps of the undulating submerged BWs, which are less noticeable in the case of the rectangular submerged BWs. Furthermore, when observing the speed gradient of the solitary wave crest passing through the set of submerged BWs, which can be traced through the streamline variation, it can be seen that the constant velocity gradient lines, which exhibit an upper and lower equal gradient pattern, occur at the front edges of the set of rectangular submerged BWs. This indicates that the water particles no longer move quickly in the forward direction after being blocked by the set of rectangular submerged BWs. By contrast, the blockages of water particles and the reduction of the propagation speed in the forward direction are less notable for the case of the solitary wave passing over the set of undulating submerged BWs.

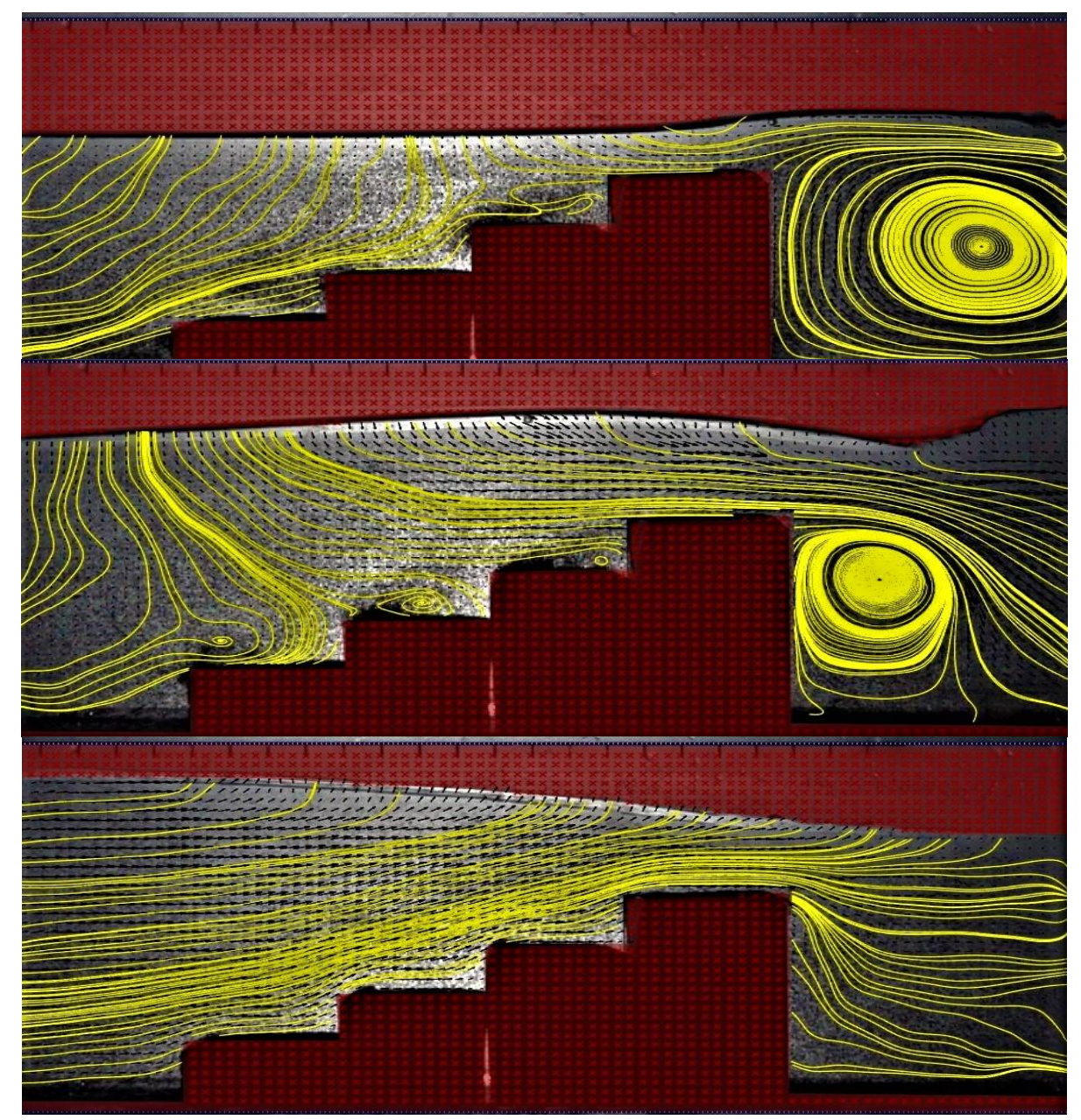

Figure 10. The streamline variation of a solitary-like wave propagating over a single set of the rectangular submerged breakwaters. 


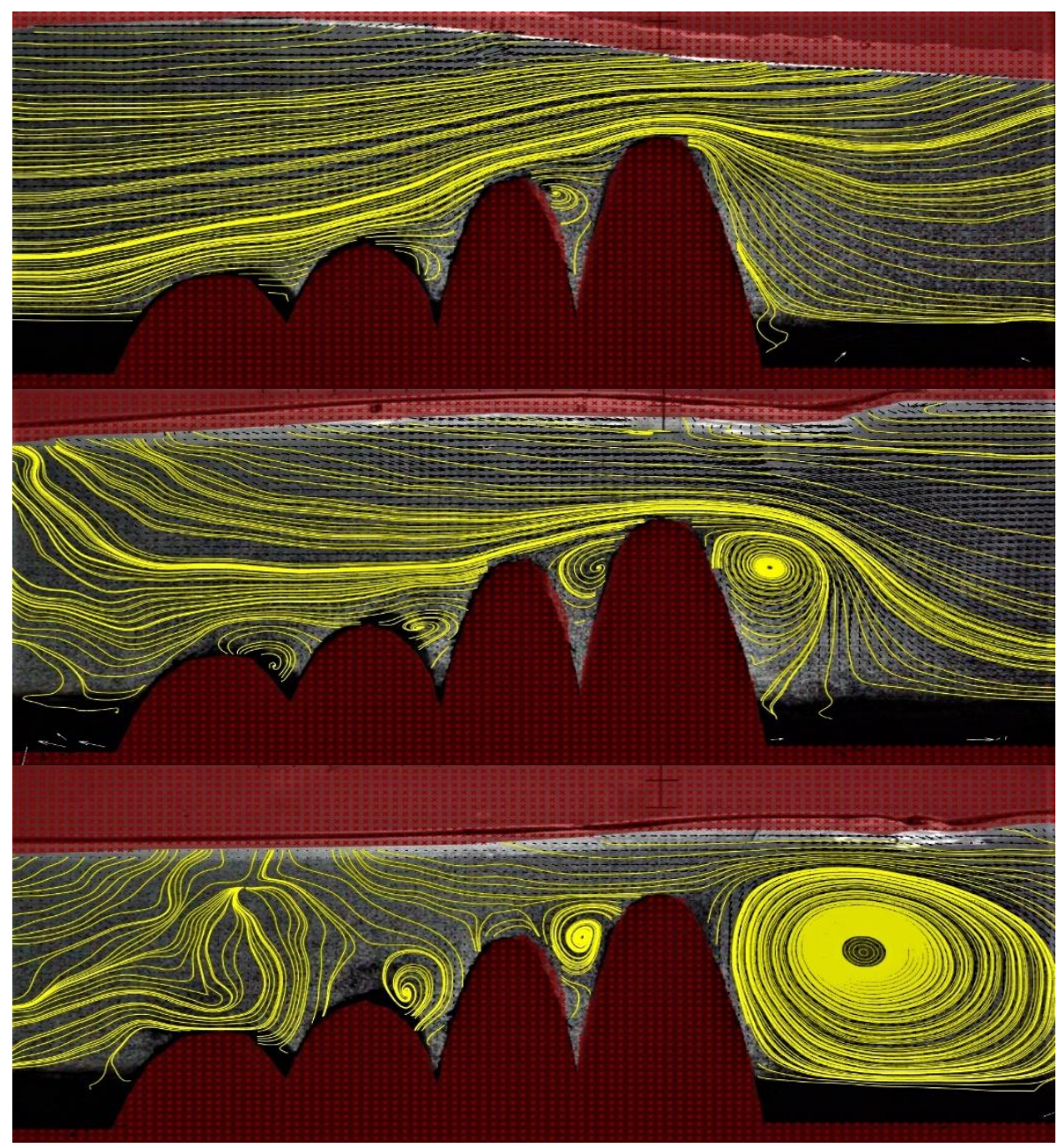

Figure 11. The streamline variation of a solitary-like wave propagating over a single set of the undulating submerged breakwaters.

\subsection{Relative Vortex Energies Induced by a Composite Set of Rectangular and Undulating BWs}

Similar to the previous section, the temporal variation of the flow field and the induced vortex when a generated solitary-like wave propagates over a composite set of submerged rectangular and undulating BWs is presented in Figure 12, with the arrows representing the incident wave direction. The omposite set of the submerged BWs is composed of two BWs, either rectangular or undulating, with a separation distance relative to the water depth $w / h=0.4$, as listed in Table 1 . The results acquired from a composite set of rectangular submerged BWs (Figure 12a) give an estimated transmission coefficient, $K_{t}$, and reflection coefficient, $K_{r}$, of approximately 0.454 and 0.256 , respectively. Moreover, from the concept of energy conservation, the sum of energy attenuation, $K_{L}$, is approximately 0.854 . From the analysis of the vortex intensity, the analyzed maximum vorticities around the center of the vortex for the first and second sets of the composite rectangular submerged BWs were approximately 55.03 1/s (Figure 13a) and 38.29 1/s (Figure 13b), respectively. The total relative vortex energy was obtained, and the relative percentage is shown in Figure 13. The total relative vortex energy of the first set of composite rectangular submerged BWs is approximately $28.29 \%$, and approximately $36.99 \%$ for the second set. Therefore, the total vortex energy accounts for $65.28 \%$ of the entire incident wave energy. 

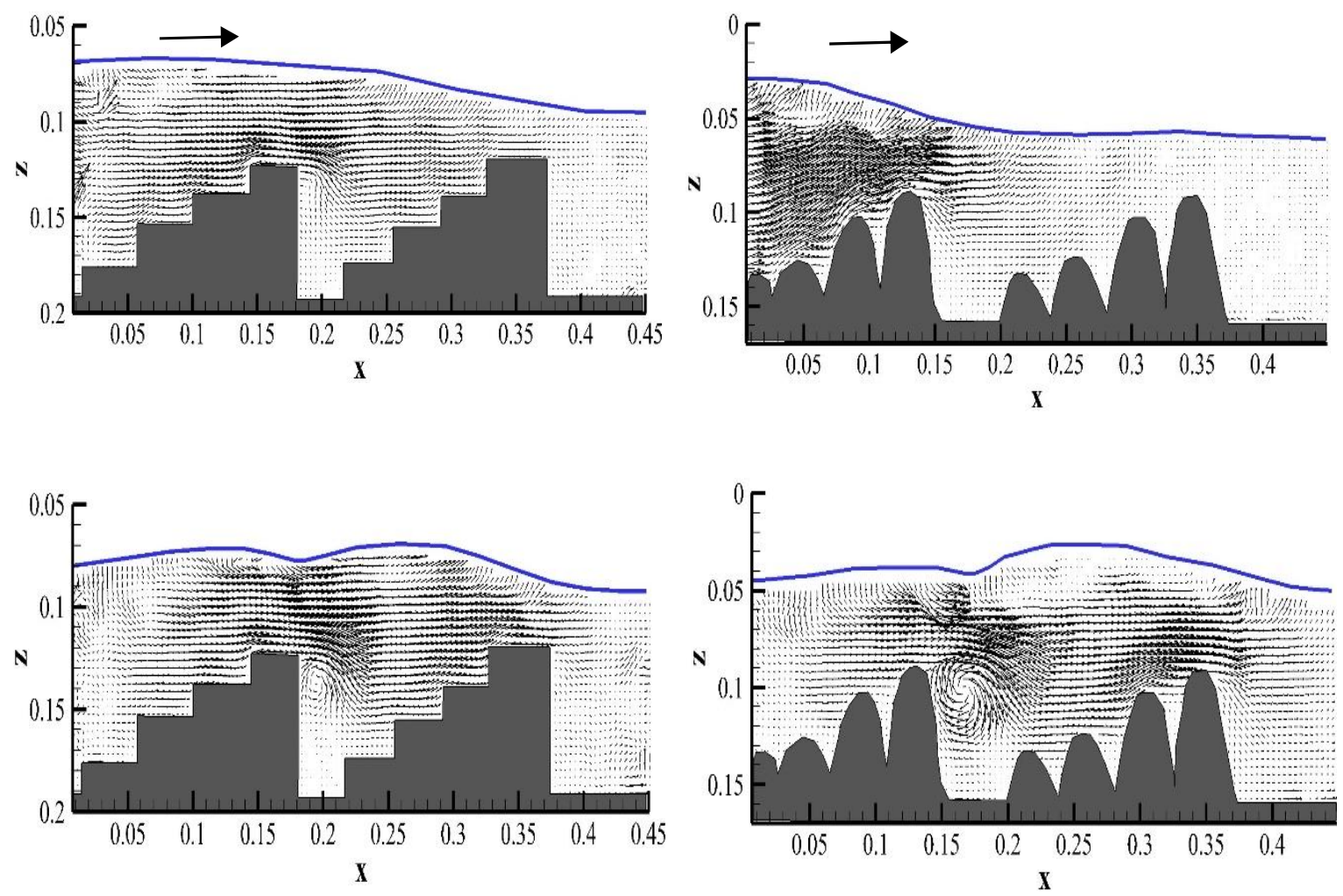

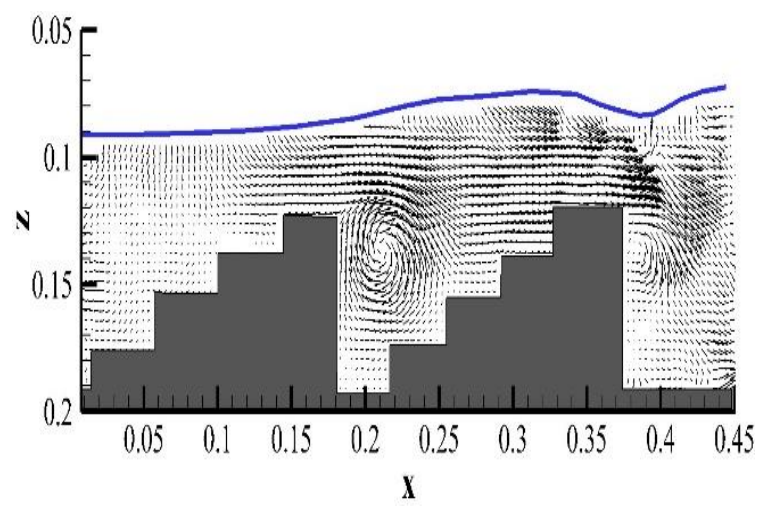

(a)

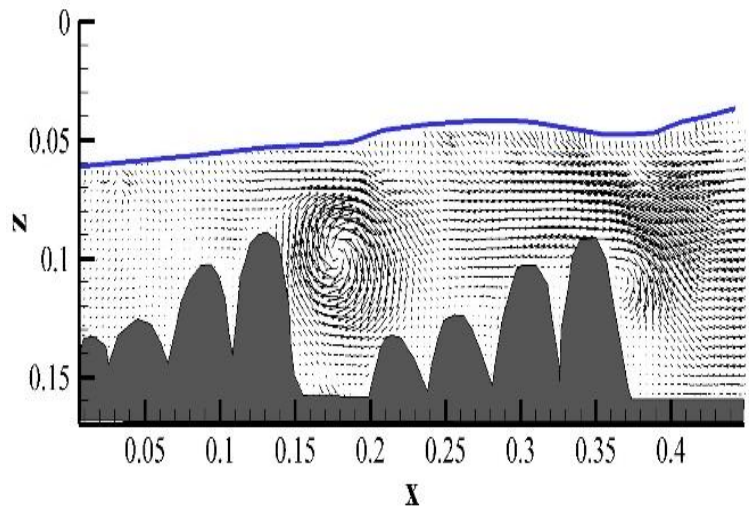

(b)

Figure 12. The vortex and velocity distribution around a composite set of submerged breakwaters with a separate distance of $w / h=0.4$ : (a) rectangular submerged breakwater; (b) undulating submerged breakwater. 

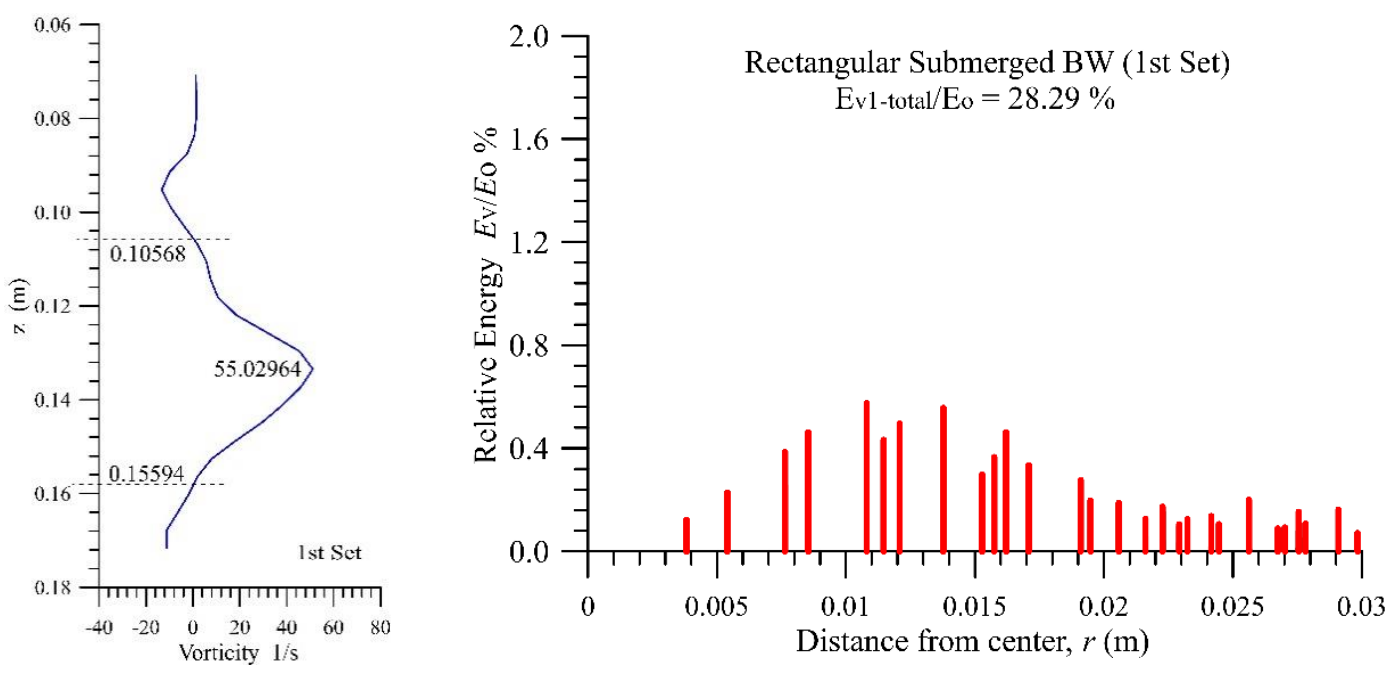

(a)
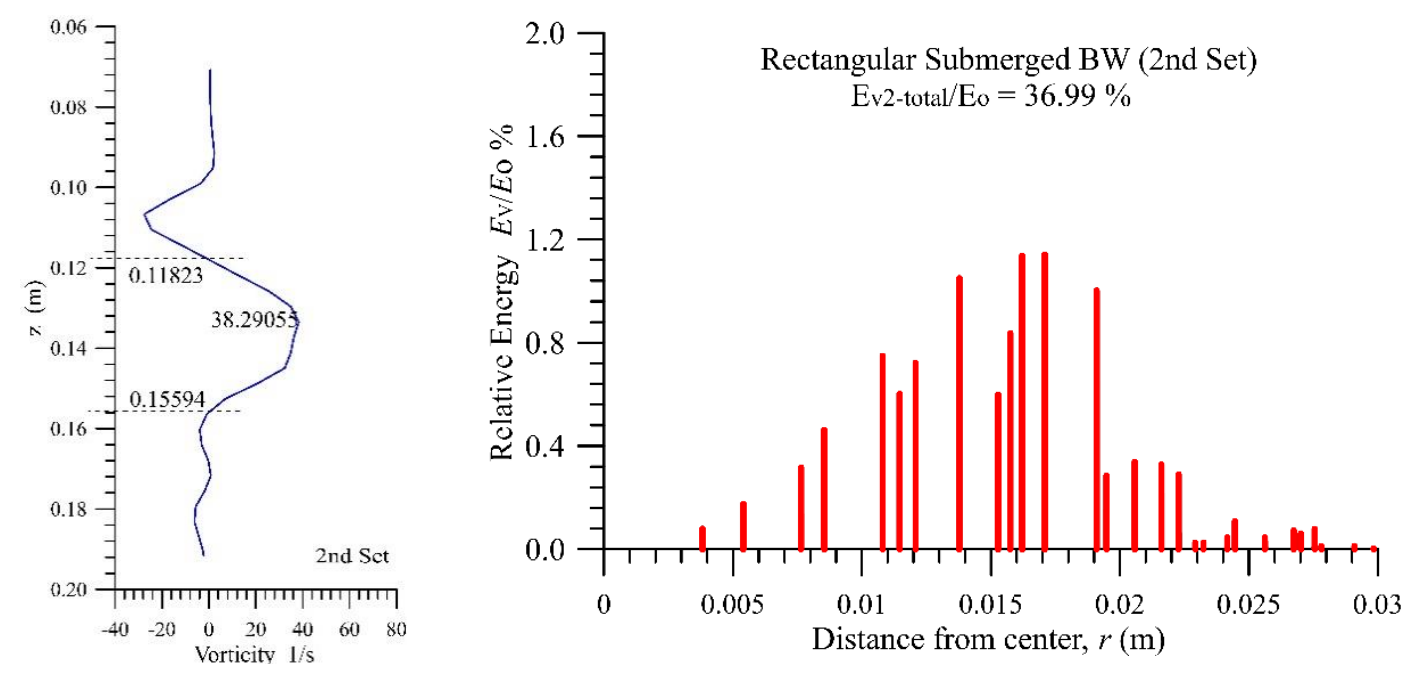

(b)

Figure 13. The vorticity distribution along the vertical line of the vortex center, and the relative vortex energy distribution of the maximum vortex induced by a solitary-like wave propagating over (a) the first set and (b) the second set of a composite set of rectangular submerged breakwaters.

Similarly, the vortex and the velocity field distribution induced by the landslide-generated, solitary-like wave propagating through the composite set of undulating submerged BWs are shown in Figure $12 \mathrm{~b}$. The vorticity distribution along the vertical line of the vortex center, and the distribution of relative vortex energy relative to the maximum vortex induced by the solitary-like wave propagating over the first and second sets of composite undulating submerged BWs, are shown in Figure 14. The maximum vorticities around the center of the first and second vortices are 86.11 1/s and 59.69 1/s, respectively, as shown in Figure 14a,b. The transmission coefficient, $K_{t}$, is estimated to be 0.736 , and the reflection coefficient, $K_{r}$, is approximately 0.189 . Thus, the sum of energy attenuation, $K_{L}$, can be calculated as 0.649 from the concept of energy conservation. The total relative vortex energies of the first and second sets of the composite undulating BWs were estimated to be $26.44 \%$ and $25.08 \%$, respectively, as shown in Figure 14. Therefore, the total vortex energy accounts for approximately $51.52 \%$ of the entire incident wave energy. When comparing the total vortex energy of the single set case with that of the composite set case, it can be seen that the composite submerged BW sets cause more wave energy attenuation. 

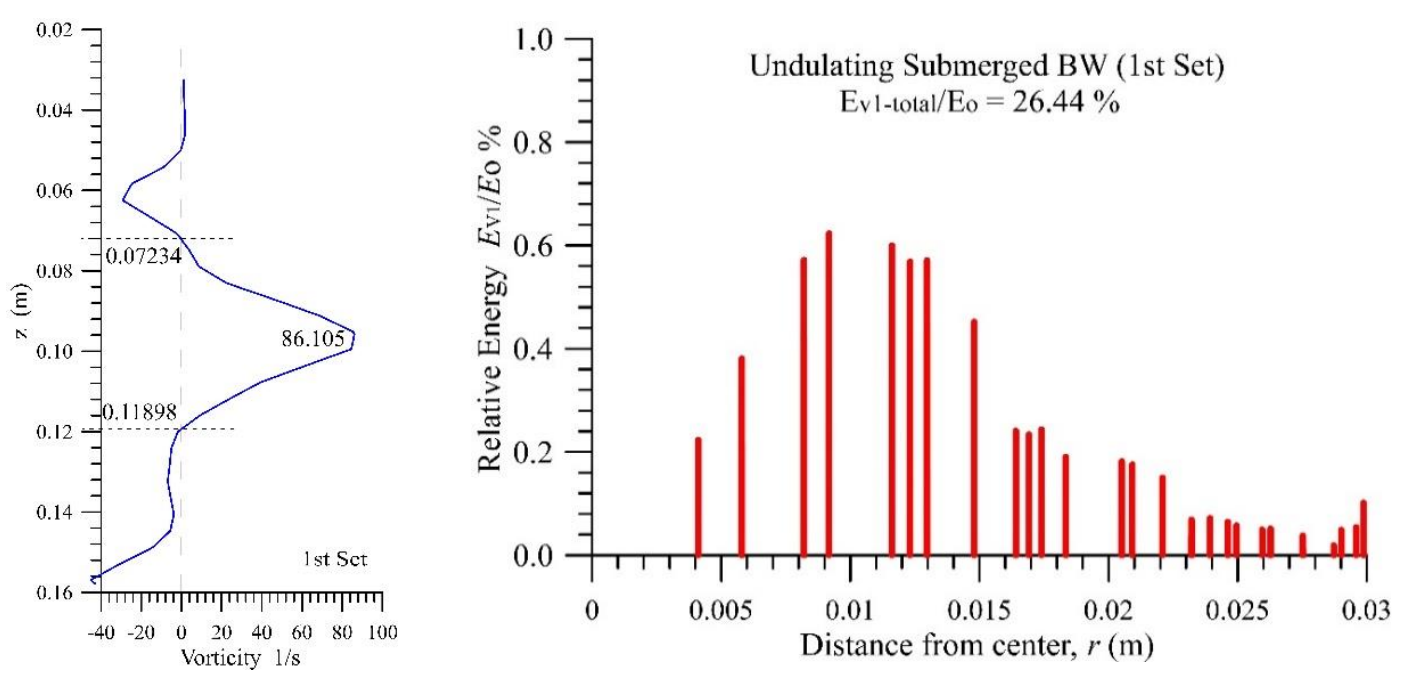

(a)
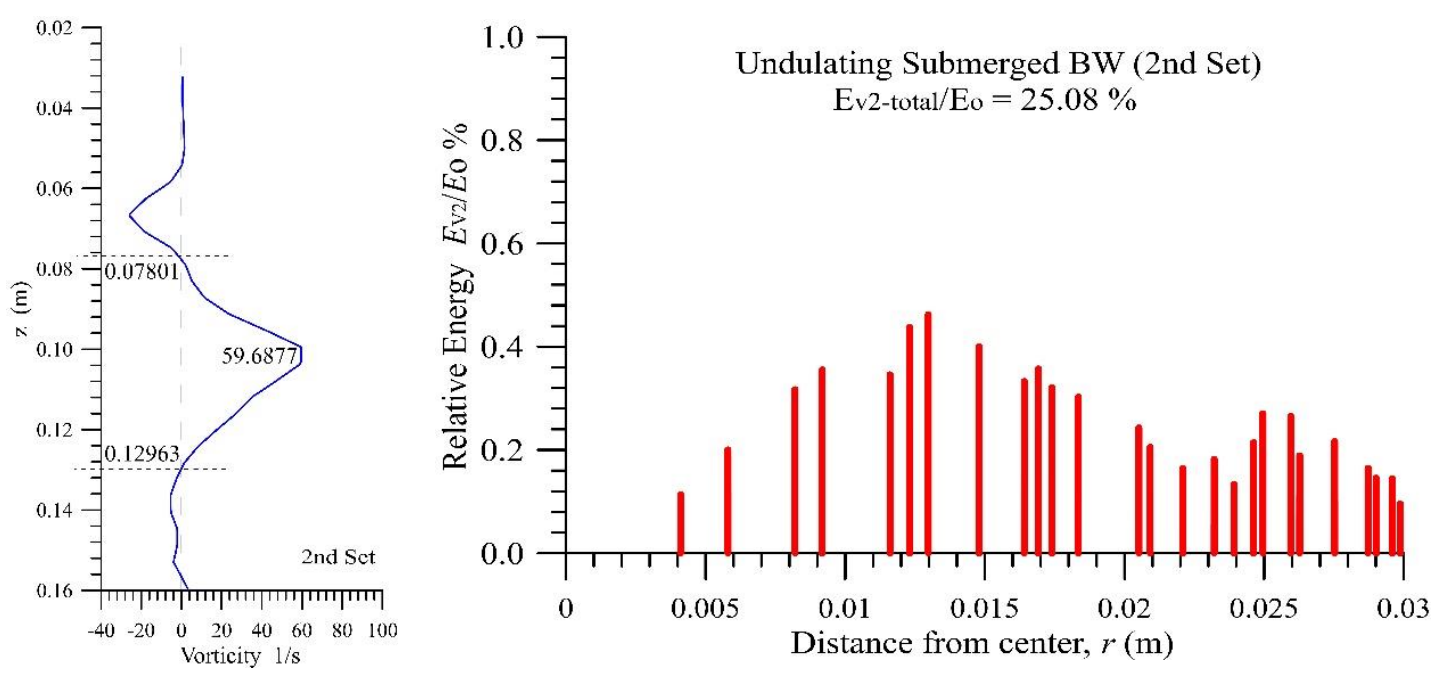

(b)

Figure 14. The vorticity distribution along the vertical line of the vortex center and relative vortex energy distribution of the maximum vortex induced by a solitary-like wave propagating over (a) the first set and (b) the second set of a composite set of undulating submerged breakwaters.

A comparison of the temporal variation and distribution of streamlines with the relative vorticity at three points in time, T1, T2, and T3, representing the generated solitary-like wave passing through the first set of the rectangular and undulating submerged BWs, respectively, is shown in Figures 15 and 16. The overall distributions of the streamlines of the generated solitary-like waves propagating over the two types of submerged BWs are similar. Still, similar to the observations in the single set case, more local small eddies occurred between the blocks of the undulating submerged BWs than between the rectangular submerged BWs. In addition, the variation in streamlines indicates that the movement of water particles was significantly hindered by the rectangular submerged BWs. When observing the vorticity distribution along the vertical line of the vortex center induced by the first BW set, as shown in Figures 15 and 16, it can be seen that the induced vortex of the rectangular BWs is relatively divergent compared with that of the undulating submerged BWs, for which the induced vortex is relatively concentrated. In addition, the magnitude of the maximum vorticity of the undulating submerged BWs appears to be larger than that of the rectangular BWs, which is the same as for the single set case. 

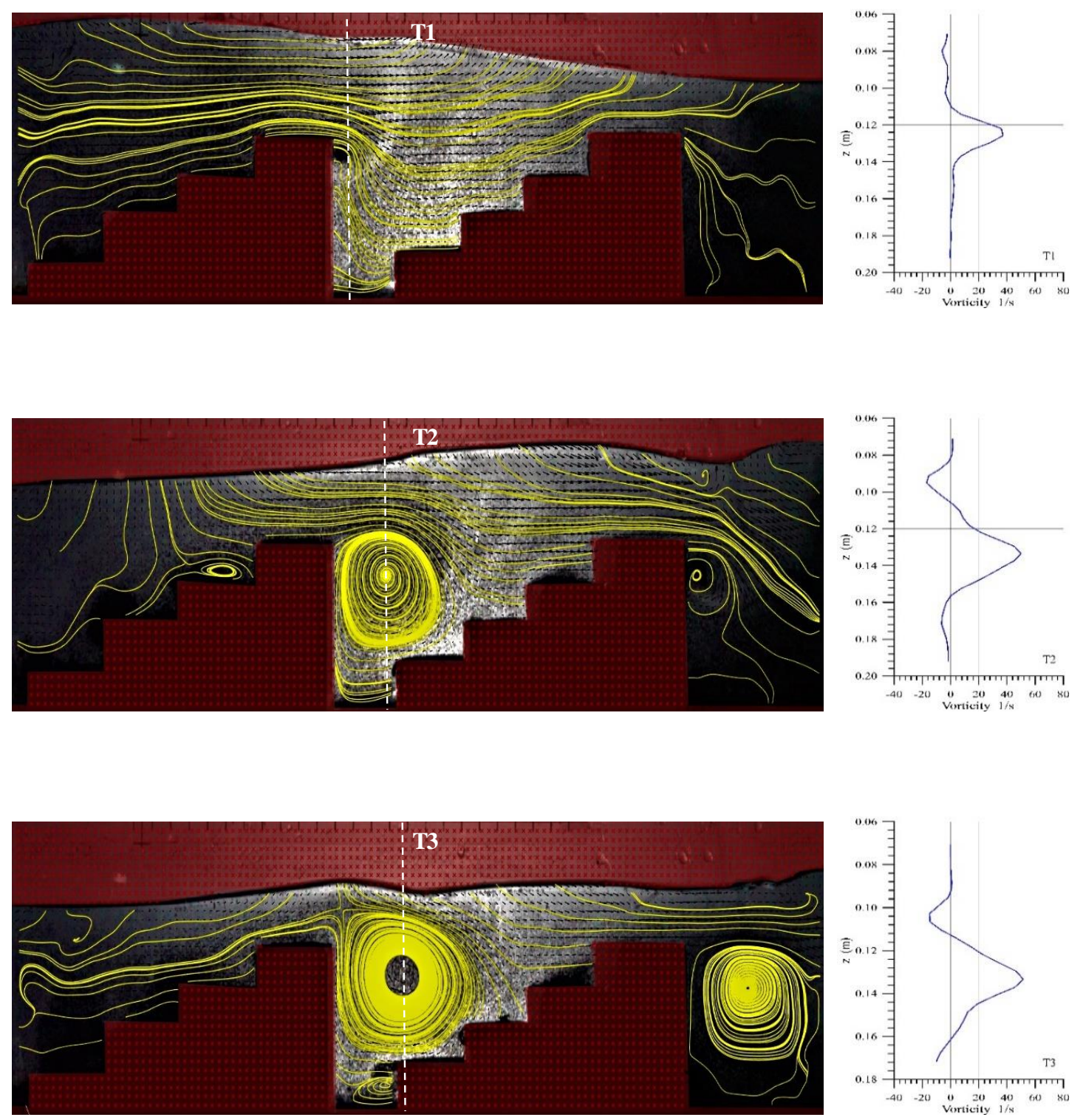

Figure 15. The temporal variation of streamlines and the vorticity distribution along the vertical line of the vortex center induced by a solitary-like wave propagating over a composite set of rectangular submerged breakwaters. 

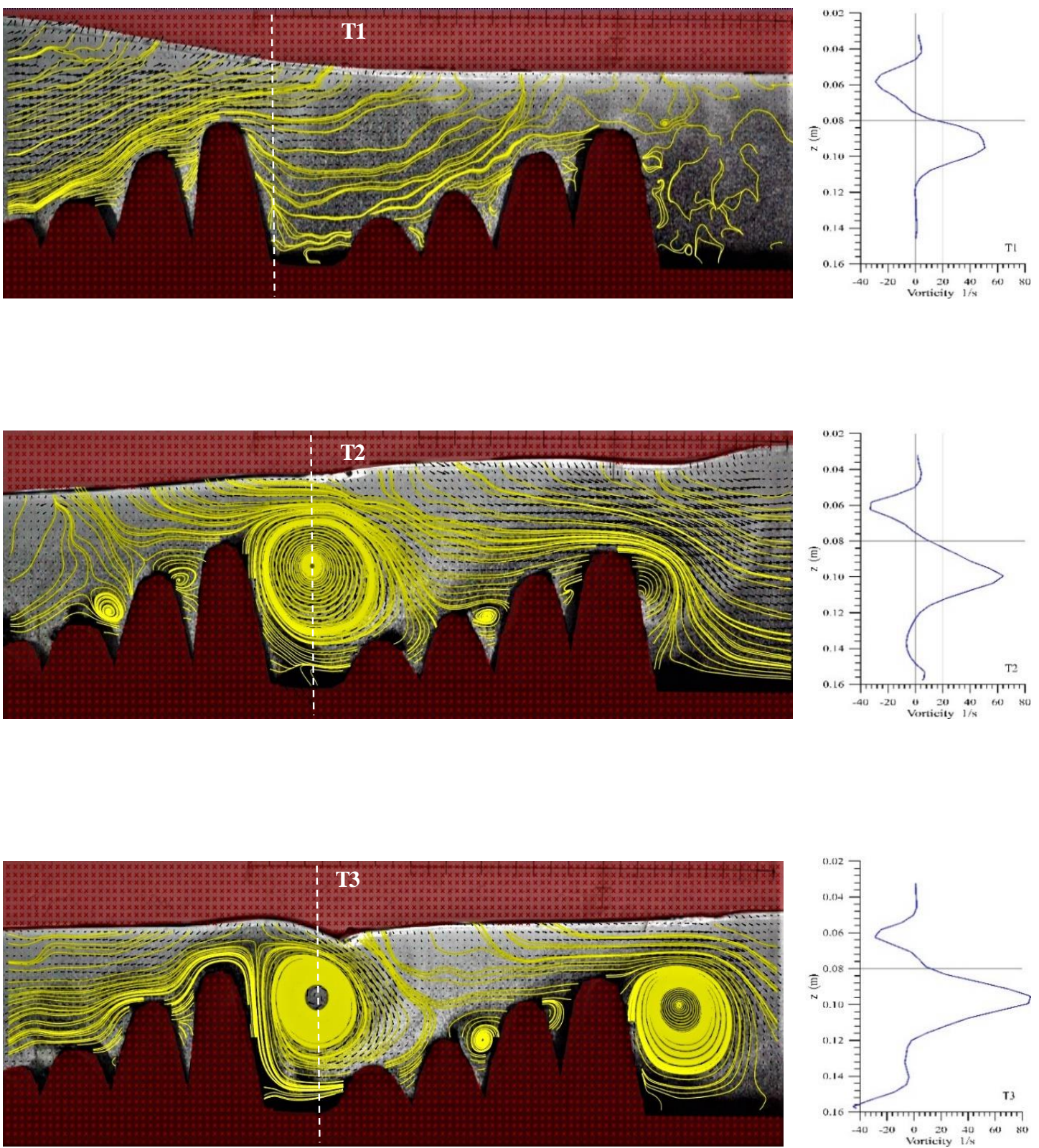

Figure 16. The temporal variation of streamlines and the vorticity distribution along the vertical line of the vortex center induced by a solitary-like wave propagating over a composite set of undulating submerged breakwaters.

\section{Conclusions}

In this study, a series of hydraulic model experiments was conducted to analyze the formation and variations of obstacle-induced vortices. These vortices were induced by landslide-generated solitary-like waves propagating over single and composite sets of rectangular and undulating submerged BWs. The induced vortices were further analyzed by PIV techniques using PIVlab, and the correlation between vortex energy and wave energy attenuation induced by different types of submerged BWs was investigated. The results showed that the sum of the relative vortex energy generated behind the composite submerged BW sets is greater than that of the single submerged BW sets. The trend of the estimated total relative vortex energy of the maximum vortices is in agreement with the sum of the energy attenuation, $K_{L}$, indicating that the attenuated wave energy is related to the induced vortices. Moreover, the total relative vortex energy of the rectangular submerged BW sets is approximately 1.29 (the single set) and 1.27 (the composite set) times larger than that of the undulating submerged BW sets. 
This shows that the rectangular submerged BW sets have stronger effects on the energy attenuation of the solitary-like wave. The magnitude of the maximum vorticity of the undulating BW sets appears to be larger than that of the rectangular BW sets; however, the total vortex energy is shown to be slightly smaller, owing to the narrower vortex area range. Finally, the induced vortex of the rectangular submerged BW sets is relatively divergent when compared with that of the undulating submerged BW sets, which is relatively concentrated.

Author Contributions: Conceptualization, methodology, R.-S.S.; resources, W.-K.W.; formal analysis, C.-Y.L. and R.-S.S.; writing—original draft, C.-Y.L. and R.-S.S.; data curation, C.-Y.L.; writing—review and editing, C.-Y.L. and R.-S.S. All authors have read and agreed to the published version of the manuscript.

Funding: This research received no external funding.

Conflicts of Interest: The authors declare no conflict of interest. The funders had no role in the design of the study; in the collection, analyses, or interpretation of data; in the writing of the manuscript, or in the decision to publish the results.

\section{References}

1. Davies, A.G.; Heathershaw, A.D. Surface-wave propagation over sinusoidally varying topography. J. Fluid Mech. 1984, 144, 419-443. [CrossRef]

2. Dalrymple, R.A.; Kirby, J.T. Water Waves Over Ripples. J. Waterw. Port Coast. Ocean Eng. 1986, 112, 309-319. [CrossRef]

3. O'Hare, T.J.; Davies, A.G. A new model for surface wave propagation over undulating topography. Coast. Eng. 1992, 18, 251-266. [CrossRef]

4. Kar, P.; Sahoo, T.; Behera, H. Effect of Bragg scattering due to bottom undulation on a floating dock. Wave Motion 2019, 90, 121-138. [CrossRef]

5. Shih, R.-S.; Weng, W.-K. A Study of Long Wave Attenuation over Composite Undulating Breakwaters. J. Coast. Res. 2016, 32, 78-90. [CrossRef]

6. Shih, R.-S.; Weng, W.-K. Experimental determination of the performance characteristics of an undulating submerged obstacle. Ships Offshore Struct. 2016, 11, 129-141. [CrossRef]

7. Shih, R.-S.; Weng, W.-K.; Li, C.-Y. Experimental Study on the Generation and Attenuation of Landslide Tsunamis. J. Coast. Res. 2018, 34, 864-876. [CrossRef]

8. Hino, M.; Yamazaki, T. Reflection and Transmission Coefficient, and Energy Loss of Surface Wave by a Vertical Barrier. Proc. Jpn. Soc. Civ. Eng. 1971, 1971, 75-80. [CrossRef]

9. Ikeda, S.; Asaeda, T.; Nomoto, K.; Kimura, E. Vortex Structure and Energy Dissipation Near a Vertical Plate under Wave Action. Doboku Gakkai Ronbunshu 1985, 1985, 87-96. [CrossRef]

10. Hokamura, T.; Ejima, T.; Imamura, I.; Tsushima, S.; Tsujimoto, G.; Yuhi, M.; Oki, K.; Yamada, F. Wave energy dissipation mechanisms of the double barrier floating breakwater. Proc. Coast. Eng. JSCE 2008, 55, 896-900. [CrossRef]

11. Umeyama, M. Investigation of Single and Multiple Solitary Waves Using Superresolution PIV. J. Waterw. Port Coast. Ocean Eng. 2013, 139, 304-313. [CrossRef]

12. Zaghian, R.; Tavakoli, M.R.; Karbasipour, M.; Nili Ahmadabadi, M. Experimental study of flow structures of a solitary wave propagating over a submerged thin plate in different angles using PIV technique. Int. J. Heat Fluid Flow 2017, 66, 18-26. [CrossRef]

13. Li, J.; Zheng, Y.-X.; Gong, P.-H.; Guan, C.-T. Numerical simulation and PIV experimental study of the effect of flow fields around tube artificial reefs. Ocean Eng. 2017, 134, 96-104. [CrossRef]

14. Chang, C.-H.; Lin, C.; Wang, K.-H.; Jaf, J.M. Numerical simulations and experimental visualizations of the vortex characteristics for a solitary wave interacting with a bottom-mounted vertical plate. J. Hydro-Environ. Res. 2018, 19, 88-102. [CrossRef]

15. Lin, C.; Wong, W.-Y.; Raikar, R.V.; Hwung, H.-H.; Tsai, C.-P. Characteristics of Accelerations and Pressure Gradient during Run-Down of Solitary Wave over Very Steep Beach: A Case Study. Water 2019, 11, 523. [CrossRef]

16. Thielicke, W.; Stamhuis, E. PIVlab—Towards User-friendly, Affordable and Accurate Digital Particle Image Velocimetry in MATLAB. J. Open Res. Softw. 2014, 2, e30. [CrossRef] 
17. Thielicke, W. The Flapping Flight of Birds: Analysis and Application. Ph.D. Thesis, Rijksuniversiteit Groningen, Groningen, The Netherlands, 2014.

18. Katell, G.; Eric, B. Accuracy of solitary wave generation by a piston wave maker. J. Hydraul. Res. 2002, 40, 321-331. [CrossRef]

19. Renouard, D.P.; Santos, F.J.S.; Temperville, A.M. Experimental study of the generation, damping, and reflexion of a solitary wave. Dyn. Atmos. Oceans 1985, 9, 341-358. [CrossRef]

20. Ippen, A.T.; Kulin, G. The shoaling and breaking of the solitary wave. Coast. Eng. Proc. 1954, 1, 4. [CrossRef]

21. Monaghan, J.J.; Kos, A. Scott Russell's wave generator. Phys. Fluids 2000, 12, 622. [CrossRef]

22. Enet, F.; Grilli, S.T. Experimental Study of Tsunami Generation by Three-Dimensional Rigid Underwater Landslides. J. Waterw. Port Coast. Ocean Eng. 2007, 133, 442-454. [CrossRef]

23. Watts, P. Tsunami Features of Solid Block Underwater Landslides. J. Waterw. Port Coast. Ocean Eng. 2000, 126, 144-152. [CrossRef]

24. Najafi-Jilani, A.; Ataie-Ashtiani, B. Estimation of near-field characteristics of tsunami generation by submarine landslide. Ocean Eng. 2008, 35, 545-557. [CrossRef]

25. Hino, M.; Yamazaki, T. Vortex formation and energy dissipation from a vertical plate. In Proceedings of the 18th Coastal Engineering, Cape Town, South Africa, 14-19 November 1982; pp. 61-65.

26. Coastal Engineering Research Center (U.S.). Shore Protection Manual; U.S. Army Coastal Engineering Research Center: Fort Belvoir, VA, USA, 1973.

27. Svendsen, I.A. Introduction to Nearshore Hydrodynamics; Advanced Series on Ocean Engineering; World Scientific: Singapore, 2006; Volume 24, ISBN 978-981-256-142-8.

28. Song, T.; Chiew, Y.M. Turbulence Measurement in Nonuniform Open-Channel Flow Using Acoustic Doppler Velocimeter (ADV). J. Eng. Mech. 2001, 127, 219-232. [CrossRef]

29. Ruonan, B.; Liekai, C.; Xingkui, W.; Danxun, L. Comparison of ADV and PIV Measurements in Open Channel Flows. Procedia Eng. 2016, 154, 995-1001. [CrossRef]

30. Goda, Y.; Suzuki, T. Estimation of incident and reflected waves in random waves. In Proceedings of the 15th Conference on Coastal Engineering, Honolulu, HI, USA, 11-17 July 1976; Volume 1, pp. 828-845. [CrossRef]

31. Mansard, E.P.D.; Funke, E.R. The Measurement of Incident and Reflected Spectra Using a Least squares Method. In Proceedings of the 17th Conference on Coastal Engineering ASCE, Sydney, Australia, 16-21 July 1980; pp. 154-172. [CrossRef]

Publisher's Note: MDPI stays neutral with regard to jurisdictional claims in published maps and institutional affiliations.

(C) 2020 by the authors. Licensee MDPI, Basel, Switzerland. This article is an open access article distributed under the terms and conditions of the Creative Commons Attribution (CC BY) license (http://creativecommons.org/licenses/by/4.0/). 